\title{
Pharmacological interventions in the treatment of the acute effects of cannabis: a systematic review of literature
}

José AS Crippa ${ }^{1 *}$, Guilherme N Derenusson ${ }^{1}$, Marcos HN Chagas ${ }^{1}$, Zerrin Atakan², Rocio Martín-Santos ${ }^{3}$, Antonio W Zuardi ${ }^{1}$ and Jaime EC Hallak

\begin{abstract}
Background: Cannabis intoxication is related to a number of physical and mental health risks with ensuing social costs. However, little attention has been given to the investigation of possible pharmacological interactions in this condition.
\end{abstract}

Objective: To review the available scientific literature concerning pharmacological interventions for the treatment of the acute effects of cannabis.

Methods: A search was performed on the Pubmed, Lilacs, and Scielo online databases by combining the terms cannabis, intoxication, psychosis, anxiety, and treatment. The articles selected from this search had their reference lists checked for additional publications related to the topic of the review.

Results: The reviewed articles consisted of case reports and controlled clinical trials and are presented according to interventions targeting the physiological, psychiatric, and cognitive symptoms provoked by cannabis. The pharmacological interventions reported in these studies include: beta-blockers, antiarrhythmic agents, antagonists of CB-1 and GABA-benzodiazepine receptors, antipsychotics, and cannabidiol.

Conclusion: Although scarce, the evidence on pharmacological interventions for the management of cannabis intoxication suggests that propanolol and rimonabant are the most effective compounds currently available to treat the physiological and subjective effects of the drug. Further studies are necessary to establish the real effectiveness of these two medications, as well as the effectiveness of other candidate compounds to counteract the effects of cannabis intoxication, such as cannabidiol and flumazenil.

Keywords: cannabis, intoxication, acute effects, psychosis, anxiety, pharmacological treatment

\section{Introduction}

Cannabis sativa has $\Delta^{9}$-tetrahydrocannabinol $\left(\Delta^{9}-\mathrm{THC}\right)$, isolated in the 1960s [1], as its main psychoactive compound. The concentration of $\Delta^{9}$-THC in the different presentations of cannabis (marijuana, hashish, skunk) is proportional to the intensity of its toxic effects. In cannabis, considered to be the most consumed illicit substance in the world [2], increased concentrations of $\Delta^{9}$ THC have been reported in recent years [3-5].

\footnotetext{
* Correspondence: jcrippa@fmrp.usp.br

'Department of Neurosciences and Behavior, Ribeirão Preto Medical School, University of São Paulo and INCT Translational Medicine (CNPq), Brazil Full list of author information is available at the end of the article
}

At the same time, there has been an increase in the number of patients reporting to specialized services with complaints related to the use of cannabis. A survey in the USA revealed that between 1992 and 1998 the demand for treatment at specialized services has doubled, with the percentage of admissions for the treatment of cannabis-related disorders (23\%) approaching the admission rates relative to cocaine (27\%) and heroine (23\%), considering all drug-related hospitalizations [6].

The use of cannabis has been associated with several psychological, behavioral, and social problems [2]. Besides the chronic effects of the continued use of cannabis, such as dependence, abstinence, varying degrees 
of cognitive impairment, and increased risk of respiratory disorders, its acute effects have also been related to significant physical and mental health problems $[7,8]$, and an increasing number of emergency admissions has been linked to cannabis use $[9,10]$.

The intoxication by cannabis is associated with subjective symptoms of euphoria, perceptual distortion, continuous giggling, sedation, lethargy, impaired perception of time, difficulties in the performance of complex mental processes, impaired judgment and social withdrawal [11]. In addition, physical signs of conjunctival hyperemia, increased appetite, dry mouth, and tachycardia can develop in the period of approximately two hours after the use of the substance [11], corresponding to the plasmatic peak of $\Delta^{9}$-THC.

In general, the acute toxicity of cannabinoids is considered to be low. Nevertheless, there are reports of death by brain infarction - especially among teenagers following the acute use of marijuana $[12,13]$ as well as of cases of patients with severe sequelae resulting from this complication [14]. Similarly, there are reports of coma in children induced by the accidental intake of cannabis [15], in addition to cases of cardiac arrhythmia [16-20], acute myocardial infarction [21], and transitory ischemic attacks [14]. Factors such as increased heart effort, elevated levels of catecholamine and carboxyhemoglobin in the blood, as well as the occurrence of postural hypotension are among the most commonly reported factors of cardiovascular disease associated with intoxication by cannabis [22].

It is known that cannabis intoxication leads to impaired motor ability, attention, and short-term memory $[8,23]$. In accordance with this, many studies have found a higher prevalence of cannabis use among drivers involved in accidents than in the general population [8].

Currently, there is consistent evidence that people who use cannabis on a regular basis have a higher proportion of acute psychiatric disorders, aggravated by other factors such as personality traits, pre-existing vulnerability, and substance use at an early age [24]. Firsttime use and the dose of cannabis are among the main factors related to this occurrence [23].

Panic and anxiety attacks are among the most commonly reported psychiatric symptoms related to cannabis intoxication and are often responsible for the discontinuation of the use of the substance [23]. Acute psychotic episodes related to cannabis intoxication are described in terms of confusion, disorientation, amnesia, depersonalization, delusions, hallucinations, paranoid ideation, psychomotor agitation, labile affect, and hostility [25]. These symptoms are usually gone after a maximum of one week abstinence [26]. In some cases, psychotic episodes secondary to the use of cannabis can persist for a substantial period of time after the acute intoxication and may have some of the features of acute schizophreniform disorders $[24,27,28]$. Further evidence is provided by a systematic review on longitudinal and population-based studies, which showed that cannabis use significantly increases the risk of developing psychotic illnesses in a dose-dependent manner [29].

There is strong evidence that cannabis use can have major detrimental effects on the course of the illness when patients with a pre-existing psychotic condition continue to use the drug [30]. In addition to worsening the outcome and exacerbating the symptoms, cannabis use by people with psychosis can lead to sudden behavioral disturbances such as increased proneness to violence, criminal activity, suspiciousness, and hallucinations [31].

Lately, attempts have been made to better understand the neurobiological mechanisms underlying cannabisrelated disorders and the functioning of the endogenous cannabinoid system. There is increasing interest for the development of medications capable to reduce the morbidity of these disorders. Because marijuana intoxication is a major public health problem with a growing demand for assistance at emergency departments, the study of possible pharmacological interventions that might help in the management of the acute effects of cannabis use is of great clinical and social relevance.

\section{Method}

This study is a bibliographic review on pharmacological interventions for the treatment of the acute effects of cannabis. The search for articles was performed on the PubMed, LILACS, and SciELO online databases using the search terms cannabis, intoxication, psychosis, anxiety, and treatment, and yielded a total of 174 matches. Additionally, an active search was conducted for related articles in the reference lists of the selected publications, which included case reports, controlled clinical trials, clinical trials of psychiatric and non-psychiatric medications, trials that promoted symptom reduction (physical, psychological or cognitive), and investigations related to the period of cannabis intoxication. Inclusion criteria were articles published in English, Spanish or Portuguese, no time limit up to October of 2011. Only those studies involving human samples were included. Taken together, the database and the hand search provided ten articles considered relevant for this review.

The results were subdivided according to interventions targetting the physiological and psychological acute effects of cannabis.

\section{Results}

The analysis of research reports of pharmacological interventions against cannabis-related problems showed 
that only a few studies have been carried out on this subject. Ten studies that fulfilled the inclusion criteria consisted of case reports and controlled clinical trials.

\section{Physiological effects}

Cardiovascular effects, such as palpitations, are among the best known clinical findings in cannabis intoxication. These symptoms have been suggested to occur as a result of the response induced by catecholamines, released by the action of the drug in the peripheral autonomic system [32]. The use of propranolol in the control of these effects, proposed by Beaconsfield et al. (1972) [33], was assessed in a placebo-controlled trial. Sulkowski et al. (1977) [34] observed that the use of this medication one hour prior to the use of marijuana significantly attenuated the occurrence of tachycardia, as well as the increase in blood pressure and conjunctival hyperemia in six healthy experienced marijuana smokers.

In two studies conducted by Huestis et al. (2001; 2007) [35,36], the compound rimonabant, previously known as SR141716, was also associated with reduced cannabis-induced tachycardia. This drug is an antagonist of CB-1 cannabinoid receptors and presented its effects at different doses (40 $\mathrm{mg}$ and $90 \mathrm{mg}$ ) administered two hours before the use of marijuana.

The tachycardia reduction observed with the use of propranolol and rimonabant was independent from pharmacokinetic interactions, which suggests a specific action of these compounds in the blockade of the activation of the sympathetic autonomic system related to the use of cannabis [20]. Although the two drugs were administered as a pretreatment in those studies, it is possible that they could be used to control tachycardia and high blood pressure in cannabis intoxication. Other forms of cardiac arrhythmia have been associated with the use of cannabis. The occurrence of arrhythmias such as atrial fibrillation seems to be associated with effects resulting from the parasympathetic stimulation induced by cannabis and observed with the use of higher doses [20]. In case reports describing the occurrence of atrial fibrillation associated with the use of cannabis, antiarrythmic agents like flecainide [20], propafenone [18], and digoxin [16] were successfully employed in the normalization of the cardiac rhythm. According to Fisher et al. (2005) [20], the use of antiarrythmic agents would be efficient in patients with no structural cardiac alterations.

The occurrence of comatose states due to cannabis intoxication is very rare and, when it happens, it usually is a result of accidental ingestion of the drug by children. Flumazenil, an antagonist of the GABA-benzodiazepine receptor complex, is generally indicated for the treatment of benzodiazepine intoxication and as a therapeutic test in coma states of unknown origin. Rubio et al. (1993) [16] described two cases of children admitted at an emergency department in a comatose state with a clinical history suggestive of intoxication and positive laboratory tests for cannabis. Both patients had a total recovery of the level of conscience after the use of flumazenil.

Cannabis intoxication rarely leads to acute respiratory deficiencies. Such deficiencies are more likely to develop in cases of pre-existing pulmonary pathology or polysubstance use. The appropriate therapeutic approach in these cases requires aggressive measures that include ventilatory support and the specific management of alterations associated with metabolic acidosis, infections, bronchospasm, and agitation. The occurrence of isolated respiratory insufficiency caused by depression of the central nervous system induced by cannabis is associated with a better prognosis [37].

The cases of apnea and depression of the central nervous system are potentially fatal and require ventilatory assistance. Flumazenil was successfully used in the cases reported by Rubio et al. (1993) [16], which support its therapeutic use in cases of cannabis-induced coma. This is consistent with other reports of reversal of the acute brain effects of the drug in different conditions, such as hepatic encephalopathy and intoxication by alcohol, carbamazepine, chloral hydrate, isoflurane, and antihistamines [38-40].

\section{Psychiatric effects}

The literature on the pharmacological management of psychotic, anxious, and affective disorders related to cannabis intoxication is limited. There is paucity of substance specific studies, since most are 'substance use' research without specifying the individual substance, such as cannabis.

In the analysis of the pharmacological management of acute psychotic states induced by cannabis, Berk et al. (1999) [41] compared the effects of olanzapine and haloperidol. In this study, 30 patients who fulfilled the DSMIV criteria for cannabis-induced psychotic disorder were randomly assigned to two groups divided according to medication (10 mg/day each) administered for four weeks. Both patient groups presented symptom reduction according to the psychiatric scales used (BPRS, CGI severity and improvement), with no statistical differences between them. The use of haloperidol, as expected, was associated with a greater occurrence of extrapyramidal side-effects and the consequent use of antiparkinsonian medication. According to some authors, the use of typical antipsychotics could intensify the use of substances, due mainly to the unpleasant side-effects of this type of medication and competitive metabolism with such substances [42]. Along these 
lines, increasing evidence supports the possible beneficial properties of atypical neuroleptics in schizophrenia associated with substance abuse disorders [43]. Likewise, as anticholinergic effects are among the symptoms of cannabis intoxication, the use of antipsychotics without such side-effects seems to be more appropriate.

Other pharmacological compounds have been tested in the management of the acute subjective states induced by cannabis. The use of rimonabant $90 \mathrm{mg} /$ day administered two hours before the use of marijuana cigarettes promoted an average reduction of $75 \%$ in the signs and symptoms of cannabis intoxication measured one hour after use [36]. Subsequently, the same group tested rimonabant in two distinct protocols, for the same purpose: daily use for 15 days in the dose of 40 $\mathrm{mg}$, and a single dose of $90 \mathrm{mg}$. The daily administration of the lower dose of rimonabant $(40 \mathrm{mg})$ attenuated the acute subjective effects after 8 but not 15 days of use [35]. These findings concerning the use of rimonabant are relevant as they underscore the role of CB-1 receptors in the mediation of cannabis-induced psychological effects, consistent with previous reports from animal studies. Nonetheless, the lack of clinical trials with the acute use of rimonabant and its important sideeffect of inducing depressive episodes [44] limit its employment in this context.

The use of propranolol in the dose of $120 \mathrm{mg}$ led to the reduction of the subjective intoxication effects when administered one hour after the use of marijuana cigarettes and lends further support to the possibility poorly investigated to date - that the action of THC on the brain could be partially mediated by beta-receptors.

Cannabidiol (CBD), a constituent of cannabis devoid of the typical psychological effects induced by other compounds of the plant, significantly attenuated the anxious and psychotic symptoms induced by $\Delta^{9}$-THC $(0,5 \mathrm{mg} / \mathrm{kg})$ in healthy volunteers when simultaneously administered in the dose of $1 \mathrm{mg} / \mathrm{kg}$ [45]. The reduction in the anxious and psychotic symptoms induced by THC reported in this study opened novel perspectives for its use in the management of psychotic and anxious states, as attested by later studies performed by our group [46-52]. However, the use of this cannabinoid in the clinical practice is still in the experimental phase and requires further investigation [53].

\section{Cognitive effects}

Only one study assessed the efficacy of pharmacological interventions on the attenuation of the cognitive impairment related to cannabis intoxication. Sulkowski et al. (1977) [34], studying the effects of propranolol $120 \mathrm{mg}$ administered one hour after the use of a marijuana cigarette with a controlled quantity of THC, reported no changes in the performance of six volunteers submitted to psychomotricity, attention, memory, and learning tests. This finding, added to the impact of the laboral and educational impairments associated with the use of cannabis, highlights the importance of the search for novel pharmacological interventions aimed at attenuating the cognitive impairment associated with intoxication by cannabis.

\section{Conclusions}

No publications were found related to the treatment of panic attacks and manic and depressive syndromes specifically associated with cannabis intoxication. We predict that in emergency settings medications with acute therapeutic effects for these conditions are used. Thus benzodiazepines, such as lorazepam and alprazolam, recommended for the acute management of panic disorder [54] can be used, but this requires research evidence for further confirmation. Similarly, manic and depressive syndromes, during the intoxication, can be managed by means of medications (benzodiazepines and antipsychotics) that attenuate important acute complaints like insomnia, anxiety, psychomotor agitation, and suicidal ideation. The use of antidepressants and mood stabilizers would be indicated only in the persistence of these symptoms, with duration beyond the intoxication period.

Cannabis intoxication is associated with significant physical and mental health impairment with resulting social costs; nonetheless, relatively few studies to date were aimed at investigating the possible pharmacological interventions in this condition [55]. However scarce, the available evidence suggests that propranolol and rimonabant are valuable tools in the therapeutic arsenal for the management of the physiological (especially cardiovascular) and subjective intoxication effects of cannabis. Flumazenil and cannabidiol were also found to counteract comatose and anxious and psychotic states, respectively, although evidence in this regard still lacks strength.

Our systematic searches revealed that articles on intoxication by cannabis are scarce and report results based on small samples. Future studies evaluating pharmacological interventions directed at the attenuation of the several acute effects induced by cannabis and at promoting greater knowledge regarding its actions are urgently necessary and opportune in the face of the increasing challenge posed by such an important public health problem.

\section{Acknowledgements}

GND is the recipient of a research grant from the National Council for Scientific and Technological Development (CNPq, Brazil). JASC (1C), JECH (2) and AWZ (1C) are recipients of CNPq Productivity Awards. The study was supported in part by the Research, Teaching, and Assistance Foundation of 
the Ribeirão Preto Medical School University Hospital (FAEPA, Brazil) and SGR2009/1435 (Departament d'Universitats Innovació i Empresa, Generalitat de Catalunya, Spain)

\section{Author details}

${ }^{1}$ Department of Neurosciences and Behavior, Ribeirão Preto Medical School, University of São Paulo and INCT Translational Medicine (CNPq), Brazil. ${ }^{2}$ Section of Neuroimaging, Box PO67, Division of Psychological Medicine \& Psychiatry, Institute of Psychiatry, King's College London, De Crespigny Park London, SE5 8AF, UK. ${ }^{3}$ Department of Psychiatry, Institute of Neurosciences, Hospital Clínic, IDIBAPS, CIBERSAM, Barcelona, Spain and INCT Translational Medicine (CNPq), Brazil.

\section{Authors' contributions}

JASC coordinated the study and drafted the manuscript. GND and JECH participated in the conception, design of the study and helped to draft manuscript. MHNC, ZA, AWZ and RMS contributed content knowledge and made contribuitions to the written manuscript. All authors read and approved the final manuscript.

\section{Competing interests}

The authors declare that they have no competing interests.

Received: 17 March 2010 Accepted: 25 January 2012

Published: 25 January 2012

\section{References}

1. Gaoni $Y$, Mechoulam R: Isolation, structure and partial synthesis of an active constituent of hashish. J Am Chem Soc 1964, 86:1646.

2. Diehl A, Cordeiro DC, Laranjeira R: Cannabis abuse in patients with psychiatric disorders: an update to old evidence. Rev Bras Psiquiatr 2010 32(Suppl 1):S41-5.

3. ElSohly MA, Ross SA, Mehmedic Z, Arafat R, Yi B, Banahan BF: Potency trends of delta9-THC and other cannabinoids in confiscated marijuana from 1980-1997. J Forensic Sci 2000, 45:24-30.

4. National Center for the Development of Natural Products: Quarterly Report Potency Monitoring Project M, 2003-August 8, 2003: NIDA Marijuana Project. University, Miss: Research Institute of Pharmaceutical Sciences, School of Pharmacy, University of Mississippi; 2003.

5. Potter DJ, Clark P, Brown MB: Potency of delta 9-THC and other cannabinoids in cannabis in England in 2005: implications for psychoactivity and pharmacology. J Forensic Sci 2008, 53:90-94.

6. Substance Abuse and Mental Health Services Administration SAMHSA: Office of Applied Studies: 1999-2000 National Household Survey on Drug Abuse U.S. Department of Health and Human Services; 2001.

7. Hall W, Solowij N: Adverse effects of cannabis. Lancet 1998, 352:1611-1616.

8. Kalant $\mathrm{H}$ : Adverse effects of cannabis on health: an update of the literature since 1996. Prog Neuropsychopharmacol Biol Psychiatry 2004, 28:849-863.

9. Bagoien G, Morken G, Zahlsen K, Aamo T, spigset O: Evaluation of a urine on-site drugs of abuse screening test in patients admitted to a psychiatric emergency unit. J Clin Psychopharmacol 2009, 29:248-254.

10. Dennis M, Babor TF, Roebuck MC, Donaldson J: Changing the focus: the case for recognizing and treating cannabis use disorders. Addiction 2002, 97(Suppl 1):4-15.

11. Diagnostic and statistical manual of mental disorders. Edited by: Association AP. Washington DC: American Psychiatric Press; , 4 1994:

12. Bachs $L$, Morland $H$ : Acute cardiovascular fatalities following cannabis use. Forensic Sci Int 2001, 124:200-203.

13. Sidney S, Beck JE, Tekawa IS, Quesenberry CP, Friedman GD: Marijuana use and mortality. Am J Public Health 1997, 87:585-590.

14. Mateo I, Infante J, Gomez Beldarrain M, Garcia-Monco JC: Cannabis and cerebrovascular disease. Neurologia 2006, 21:204-208.

15. Appelboam A, Oades PJ: Coma due to cannabis toxicity in an infant. Eur J Emerg Med 2006, 13:177-179.

16. Rubio F, Quintero S, Hernandez A, Fernandez S, Cozar L, Lobato IM, Pantoja S: Flumazenil for coma reversal in children after cannabis. Lancet 1993, 341:1028-1029

17. Singh GK: Atrial fibrillation associated with marijuana use. Pediatr Cardiol 2000, 21:284.
18. Kosior DA, Filipiak KJ, Stolarz P, Opolski G: Paroxysmal atrial fibrillation following marijuana intoxication: a two-case report of possible association. Int J Cardiol 2001, 78:183-184.

19. Charbonney E, Sztajzel JM, Poletti PA, Rutschmann O: Paroxysmal atrial fibrillation after recreational marijuana smoking: another "holiday heart"? Swiss Med Wkly 2005, 135:412-414.

20. Fisher BA, Ghuran A, Vadamalai V, Antonios TF: Cardiovascular complications induced by cannabis smoking: a case report and review of the literature. Emerg Med J 2005, 22:679-680.

21. Mittleman MA, Lewis RA, Maclure M, Sherwood JB, Muller JE: Triggering myocardial infarction by marijuana. Circulation 2001, 103:2805-2809.

22. Jones RT: Cardiovascular system effects of marijuana. J Clin Pharmacol 2002, 42:58S-63S.

23. Solowij N, Pesa N: Cognitive abnormalities and cannabis use. Rev Bras Psiquiatr 2010, 32(Suppl 1):S31-40.

24. Johns A: Psychiatric effects of cannabis. Br J Psychiatry 2001, 178:116-122.

25. Ben Amar M, Potvin S: Cannabis and psychosis: what is the link? J Psychoactive Drugs 2007, 39:131-142.

26. Lishman WA: Organic Psychiatry: The Psychological Consequences of Cerebral Disorder. 3 edition. Oxford: Blackwell; 1998.

27. Semple DM, Mclntosh AM, Lawrie SM: Cannabis as a risk factor for psychosis: systematic review. J Psychopharmacol 2005, 19:187-194.

28. Fergusson DM, Horwood LJ, Ridder EM: Tests of causal linkages between cannabis use and psychotic symptoms. Addiction 2005, 100:354-366.

29. Moore TH, Zammit S, Lingford-Hughes A, Barnes TR, Jones PB, Burke M, Lewis G: Cannabis use and risk of psychotic or affective mental health outcomes: a systematic review. Lancet 2007, 370:319-328.

30. Mueser KT, Yarnold PR, Rosenberg SD, Swett C Jr, Miles KM, Hill D: Substance use disorder in hospitalized severely mentally ill psychiatric patients: prevalence, correlates, and subgroups. Schizophr Bull 2000, 26:179-192.

31. Miles H, Johnson S, Amponsah-Afuwape S, Finch E, Leese M, Thornicroft G Characteristics of subgroups of individuals with psychotic illness and a comorbid substance use disorder. Psychiatr Serv 2003, 54:554-561.

32. Brust JC: Other agents. Phencyclidine, marijuana, hallucinogens, inhalants, and anticholinergics. Neurol Clin 1993, 11:555-561.

33. Beaconsfield P, Ginsburg J, Rainsbury R: Marihuana smoking. Cardiovascular effects in man and possible mechanisms. $N$ Engl J Med 1972, 287:209-212

34. Sulkowski A, Vachon L, Rich ES Jr: Propranolol effects on acute marihuana intoxication in man. Psychopharmacology (Berl) 1977, 52:47-53.

35. Huestis MA, Boyd SJ, Heishman SJ, Preston KL, Bonnet D, Le Fur G, Gorelick DA: Single and multiple doses of rimonabant antagonize acute effects of smoked cannabis in male cannabis users. Psychopharmacology (Berl) 2007, 194:505-515.

36. Huestis MA, Gorelick DA, Heishman SJ, Preston KL, Nelson RA, Moolchan ET, Frank RA: Blockade of effects of smoked marijuana by the CB1-selective cannabinoid receptor antagonist SR141716. Arch Gen Psychiatry 2001, 58:322-328.

37. Wilson KC, Saukkonen JJ: Acute respiratory failure from abused substances. J Intensive Care Med 2004, 19:183-193.

38. Roald OK, Dahl V: Flunitrazepam intoxication in a child successfully treated with the benzodiazepine antagonist flumazenil. Crit Care Med 1989, 17:1355-1356.

39. Weinbroum A, Halpern P, Geller E: The use of flumazenil in the management of acute drug poisoning-a review. Intensive Care Med 1991, 17(Suppl 1):S32-38.

40. Lassaletta A, Martino R, Gonzalez-Santiago P, Torrijos C, Cebrero M, GarciaFrias E: Reversal of an antihistamine-induced coma with flumazenil. Pediatr Emerg Care 2004, 20:319-320.

41. Berk M, Brook S, Trandafir Al: A comparison of olanzapine with haloperidol in cannabis-induced psychotic disorder: a double-blind randomized controlled trial. Int Clin Psychopharmacol 1999, 14:177-180.

42. McEvoy JP, Freudenreich O, Levin ED, Rose JE: Haloperidol increases smoking in patients with schizophrenia. Psychopharmacology (Berl) 1995, 119:124-126.

43. Green Al, Noordsy DL, Brunette MF, O'Keefe C: Substance abuse and schizophrenia: pharmacotherapeutic intervention. J Subst Abuse Treat 2008, 34:61-71.

44. Doggrell SA: Is rimonabant efficacious and safe in the treatment of obesity? Expert Opin Pharmacother 2008, 9:2727-2731. 
45. Zuardi AW, Shirakawa I, Finkelfarb E, Karniol IG: Action of cannabidiol on the anxiety and other effects produced by delta 9-THC in normal subjects. Psychopharmacology (Berl) 1982, 76:245-250.

46. Crippa JA, Zuardi AW, Hallak JE: Therapeutical use of the cannabinoids in psychiatry. Rev Bras Psiquiatr 2010, 32(Suppl 1):S56-66.

47. Zuardi AW, Crippa JA, Hallak JE, Moreira FA, Guimaraes FS: Cannabidiol, a Cannabis sativa constituent, as an antipsychotic drug. Braz J Med Biol Res 2006, 39:421-429.

48. Crippa JA, Zuardi AW, Garrido GE, Wichert-Ana L, Guarnieri R, Ferrari L, Azevedo-Marques PM, Hallak JE, McGuire PK, Filho Busatto G: Effects of cannabidiol (CBD) on regional cerebral blood flow. Neuropsychopharmacology 2004, 29:417-426.

49. Zuardi AW, Crippa JA, Hallak JE: Cannabis sativa: the plant that can induce unwanted effects and also treat them. Rev Bras Psiquiatr 2010, 32(Suppl 1):S1-2.

50. Bergamaschi MM, Queiroz RH, Chagas MH, de Oliveira DC, De Martinis BS, Kapczinski F, Quevedo J, Roesler R, Schröder N, Nardi AE, Martín-Santos R, Hallak JE, Zuardi AW, Crippa JA: Cannabidiol reduces the anxiety induced by simulated public speaking in treatment-naive social phobia patients. Neuropsychopharmacology 2011, 36:1219-1226.

51. Crippa JA, Derenusson GN, Ferrari TB, Wichert-Ana L, Duran FL, MartinSantos R, Simões MV, Bhattacharyya S, Fusar-Poli P, Atakan Z, Santos Filho A, Freitas-Ferrari MC, McGuire PK, Zuardi AW, Busatto GF, Hallak JE: Neural basis of anxiolytic effects of cannabidiol (CBD) in generalized social anxiety disorder: a preliminary report. J Psychopharmacol 2011, 25:121-130.

52. Crippa JA, Zuardi AW, Martín-Santos R, Bhattacharyya S, Atakan Z, McGuire P, Fusar-Poli P: Cannabis and anxiety: a critical review of the evidence. Hum Psychopharmacol 2009, 24:515-523.

53. Saito VM, Wotjak CT, Moreira FA: Pharmacological exploitation of the endocannabinoid system: new perspectives for the treatment of depression and anxiety disorders? Rev Bras Psiquiatr 2010, 32(Suppl 1): S7-14.

54. Baldwin DS, Anderson IM, Nutt DJ, Bandelow B, Bond A, Davidson JR, den Boer JA, Fineberg NA, Knapp M, Scott J, Wittchen HU: Evidence-based guidelines for the pharmacological treatment of anxiety disorders: recommendations from the British Association for Psychopharmacology. J Psychopharmacol 2005, 19:567-596.

55. Budney AJ, Vandrey RG, Stanger C: Pharmacological and psychosocial interventions for cannabis use disorders. Rev Bras Psiquiatr 2010, 32(Suppl 1):S46-55.

doi:10.1186/1477-7517-9-7

Cite this article as: Crippa et al.: Pharmacological interventions in the treatment of the acute effects of cannabis: a systematic review of literature. Harm Reduction Journal 2012 9:7.

\section{Submit your next manuscript to BioMed Central and take full advantage of:}

- Convenient online submission

- Thorough peer review

- No space constraints or color figure charges

- Immediate publication on acceptance

- Inclusion in PubMed, CAS, Scopus and Google Scholar

- Research which is freely available for redistribution

Submit your manuscript at www.biomedcentral.com/submit
Biomed Central 